OPEN ACCESS

Edited by:

Zexian Liu,

Sun Yat-sen University Cancer Center

(SYSUCC), China

Reviewed by:

Jianping Guo,

Sun Yat-sen University, China

Xiangpeng Dai,

Jilin University, China

Jinfang Zhang,

Wuhan University, China

*Correspondence: Feng Pan

cqp@@otmail.com

Bin Wang

wb_tmmu@126.com

${ }^{t}$ These authors have contributed equally to this work

Specialty section: This article was submitted to Gastrointestinal Cancers: Colorectal Cancer, a section of the journal

Frontiers in Oncology

Received: 28 July 2021 Accepted: 22 September 2021 Published: 12 October 2021

Citation:

Zhang X, Li Q, DU A, Li Y, Shi Q Chen $Y$, Zhao $Y$, Wang $B$ and Pan $F$

(2021) Adipocytic Glutamine Synthetase Upregulation via Altered Histone Methylation Promotes 5FU

Chemoresistance in Peritoneal Carcinomatosis of Colorectal Cancer.

Front. Oncol. 11:748730.

doi: 10.3389/fonc.2021.748730

\section{Adipocytic Glutamine Synthetase Upregulation via Altered Histone Methylation Promotes 5FU Chemoresistance in Peritoneal Carcinomatosis of Colorectal Cancer}

\author{
Xuan Zhang ${ }^{1,2 \dagger}$, Qing $\mathrm{Li}^{3 \dagger}$, Aibei $\mathrm{Du}^{2 \dagger}$, Yifei $\mathrm{Li}^{4}$, Qing Shi ${ }^{5}$, Yanrong Chen ${ }^{1}$, Yang Zhao ${ }^{1}$, \\ Bin Wang ${ }^{2 *}$ and Feng Pan ${ }^{1 *}$ \\ ${ }^{1}$ Department of Oncology, Southwest Hospital, Army Medical University (Third Military Medical University), \\ Chongqing, China, 2 Department of Gastroenterology, Daping Hospital, Army Medical University (Third Military Medical \\ University), Chongqing, China, ${ }^{3}$ Department of Science and Education, The People's Hospital of Tongliang District, \\ Chongqing, China, ${ }^{4}$ Department of Hematology, The Second Affiliated Hospital of Chongqing Medical University, \\ Chongqing, China, ${ }^{5}$ Department of Respiratory Medicine, The People's Hospital of Tongliang District, Chongqing, China
}

The development of resistance to 5 -fluorouracil (5FU) chemotherapy is a major handicap for sustained effective treatment in peritoneal carcinomatosis $(\mathrm{PC})$ of colorectal cancer $(\mathrm{CRC})$. Metabolic reprogramming of adipocytes, a component of the tumor microenvironment and the main composition of peritoneum, plays a significant role in drug resistance of PC, with the mechanisms being not fully understood. By performing metabolomics analysis, we identified glutamine (GIn), an important amino acid, inducing resistance to 5FU-triggered tumor suppression of CRC-PC through activating mTOR pathway. Noteworthily, genetic overexpression of glutamine synthetase (GS) in adipocytes increased chemoresistance to 5FU in vitro and in vivo while this effect was reversed by pharmacological blockage of GS. Next, we showed that methionine metabolism were enhanced in amino acid omitted from CRC-PC of GS transgenic ( $\left.\mathrm{Tg}^{\mathrm{GS}}\right)$ mice, increasing intracellular levels of S-carboxymethy-L-cys. Moreover, loss of dimethylation at lysine 4 of histone $\mathrm{H} 3(\mathrm{H} 3 \mathrm{k} 4 \mathrm{me} 2)$ was found in adipocytes in vitro, which may lead to increased expression of GS. Furthermore, biochemical inhibition of lysine specific demethylase 1 (LSD1) restored H3k4me2, thereby reducing GS-induced chemoresistance to 5FU. Our findings indicate that GS upregulation-induced excessive of GIn in adipocytes via altered histone methylation is potential mediator of resistance to 5FU chemotherapy in patients with CRC-PC.

Keywords: peritoneal carcinomatosis, colorectal cancer, chemoresistance, glutamine synthetase, histone methylation 


\section{INTRODUCTION}

Colorectal cancer (CRC) is the third most commonly diagnosed cancers and the fourth leading cause of cancer-associated mortality worldwide $(1,2)$. Metastasis is the main cause of poor outcome in CRC patients. Among all the metastasis access, the peritoneum is the second most common site for CRC metastasis, and $4.8 \%$ of CRC patients exhibit evidence of synchronous peritoneal carcinomatosis (PC) while 19\% show characteristic of metachronous PC $(3,4)$. PC is a well-known indicator of poor prognosis of CRC, and the median survival time of patients with PC is only 6-11 months $(4,5)$.

5 -fluorouracil (5FU), a thymidylate synthase inhibitor, is often used during early intraperitoneal chemotherapy. 5FUbased chemotherapy is a standard treatment for patients with metastatic CRC (6). 5FU acts during the S-phase of the cell cycle and blocks purine synthesis by inhibiting thymidylate synthetase activity, thereby reducing DNA replication and repair, leading to suppression of tumor cell growth $(7,8)$. However, resistance to 5FU treatment in patients with CRC remains common, promoting tumor recurrence and metastasis (9), with the mechanisms being not fully known. Therefore, it is crucial to get a better understanding of the underlying mechanisms of resistance to $5 \mathrm{FU}$ chemotherapy for the management of patients with CRC- PC.

Tumor microenvironment (TME), a heterogeneous ecosystem contributing to tumor progression, consists of infiltrating immune cells, mesenchymal support cells, and matrix components. As the important component of TME, adipocytes play essential roles in facilitating tumor growth and mediating drug resistance (10). However, it is still unclear whether adipocytes, the main composition of peritoneum, mediate resistance to 5FU chemotherapy in CRC-PC. Besides, as abnormal adipocyte metabolism in dysfunctional adipose tissue induces the development of cancers and drug resistance (11), and 5FU chemoresistance may result from altered regulation of nucleotide metabolism, amino acid metabolism, and oxygen metabolism (12), we hypothesized that adipocytederived cytokines or metabolites might contribute to chemoresistance in CRC-PC.

Glutamine (Gln), one of the adipocyte-derived metabolites, has been found to mediate chemoresistance by several mechanisms (13). Drug resistance caused by increased intracellular glutamine content is directly associated with the dynamic change of glutamine transporters (14). Glutamine has been also shown to promote chemoresistance via the mammalian target of rapamycin (mTOR) activation (15). Glutamine synthetase (GS), an ATP-dependent metalloenzyme, combines ammonium and glutamate into Gln and is associated with chemoresistance (16). Although common mechanisms leading to 5FU resistance have been well-documented in the literature, the role of Gln and GS in 5FU resistance needs to be clarified.

mTOR, a specificity protein kinase phosphorylating serine/ theonine, plays substantial roles in cell proliferation, survival, autophagy, and metabolism (17). Dysregulation and activating mutations of mTOR have been reported in various types of human cancers, and hence mTOR inhibitors have been approved for the treatment of malignancies (18). mTOR signaling also plays important roles in drug resistance of CRC (19). As a drugresistance-related protein, mTOR mediates $5 \mathrm{FU}$ drug resistance (20).

Histones are basic chromosomal proteins that play essential structural and functional roles in gene regulation and epigenetic silencing (21). Histone proteins can be reversibly modified by methylation, acetylation, ubiquitination, and phosphorylation. These modifications of histone structures have been shown to play crucial roles in cancer initiation and progression with different mechanisms (22). Histone methylation can be capable of altering chromatin structure and regulating gene expression. Additionally, histone methyltransferase activity has been found to be involved in $5 \mathrm{FU}$ chemoresistance in CRC $(9,23)$. However, at this time, it remains unclear whether altered histone methyltransferase activity might affect adipocyte metabolism and mediate 5FU resistance in CRC-PC. In order to improve the therapeutic efficacy of 5FU and elucidate the mechanism underlying the development of 5FU resistance in patients with $\mathrm{CRC}$, we firstly identified glutamine (Gln) as an important amino acid to induce resistance to 5FU-triggered tumor suppression of CRC-PC via activating mTOR pathway using metabolomics analysis. We then examined whether altered genetic expression of glutamine synthetase (GS) in adipocytes can affect chemoresistance to $5 \mathrm{FU}$ in vitro and in vivo. Next, we explored methionine metabolism in amino acid omitted from CRC-PC of GS transgenic $\left(\mathrm{Tg}^{\mathrm{GS}}\right)$ mice and the underlying mechanisms of 5FU resistance through regulation of histone $\mathrm{H} 3$ lysine 4 dimethylation (H3k4me2) in adipocytes in vitro.

\section{MATERIALS AND METHODS}

\section{Cell Culture}

The mouse CRC cell lines CT26, MC38, mouse melanoma cell line B16, human CRC cell lines SW-480 and HCT-116 were purchased from American Type Culture Collection (ATCC, Rockville, MD, USA). Those cells have been authenticated and checked for mycoplasma by JENNIO Biological Technology (Guangzhou, China). The cell lines were maintained in continuous exponential growth by twice weekly passage in Dulbecco modified Eagle's medium (DMEM, Life Technologies, Inc., Gaithersburg, MD, USA) supplemented with $10 \%$ fetal bovine serum and cultured at $37^{\circ} \mathrm{C}$ with $5 \%$ $\mathrm{CO} 2$. Each cell line was split regularly before attaining 70 $80 \%$ confluence.

The "cocktail method" was used to induce differentiation based on optimization of a method previously described $(24,25)$. Briefly, the 3T3-L1 cells $\left(2 \times 10^{5}\right.$ cells $\left./ \mathrm{ml}\right)$ were grown to confluence in DMEM with 10\% FBS in T75 cell culture flask (day -2). On day 0 , the media were changed to DMEM with supplements plus $10 \%$ fetal bovine serum, $10 \mu \mathrm{g} / \mathrm{ml}$ insulin (Sigma-Aldrich; Merck KGaA, Darmstadt, Germany), $1 \mu \mathrm{mol} / \mathrm{L}$ dexamethasone (Sigma-Aldrich; Merck KGaA, Darmstadt, Germany), and 0.5 mM isobutylmethylxanthine (IBMX, Sigma, 
St. Louis, MO, USA). On day +2, dexamethasone and IBMX were removed from the media, and on day +4 insulin was removed. Media changes were performed every 2 days until use. The CM from adipocytes (\#3T3-L1-CM) were harvested between days +10 and +14 .

\section{Mouse Experiments}

All the animal experiments were approved by the Laboratory Animal Welfare and Ethics Committee of Army Medical University (AMUWEC20181835) and performed in accordance with the Guide for the care and use of laboratory animals published by the US National Institutes of Health (publication no.85-23, revised 1996). Four-to-six-week-old female BALB/c mice (body weight: 18-20 g) were purchased from the Institute of Experimental Animal of Army Medical University (Chongqing, China). The adipocyte-specific transgenic GS-expressing C57BL/6 mice (Cyagen Biosciences, China) were generated by inserting a DNA pRP(Exp)-Promoter_5411bp (Adiponectin) $>$ mGlul [ORF031394]. Primers for PCR genotyping of the GS forward: G A C A T G A T G C A G G T C C T G A T T G G; rever s e : GGGTCTTGCAGCGCAGTCCTT. Transgenic mice yield a PCR product of $248 \mathrm{bp}$. Mice were maintained under specific pathogenfree conditions and had ad libitum access to food and water. CT26 cells $\left(1.0 \times 10^{6} / 100 \mu \mathrm{l} \mathrm{PBS}\right)$ were intraperitoneally injected into female BALB/c mice, or MC38 cells $\left(1.0 \times 10^{6} / 100 \mu \mathrm{l}\right.$ PBS $)$ were intraperitoneally injected into GS-expressing C57BL/6 mice to establish a peritoneal metastasis model according to Abdelkader Taibi et al. (26) and Liping Yang et al. (27). CT26 cells $\left(1.0 \times 10^{6} \%\right.$ $100 \mu \mathrm{l}$ PBS) were injected subcutaneously into female BALB/c mice to establish a subcutaneous xenograft model. CT26 cells $\left(1.0 \times 10^{6} \%\right.$ $100 \mu \mathrm{l}$ PBS) were also injected into the colon to establish a in situ model of CRC. 5FU was administrated intraperitoneally once a day (50 mg/kg). Different kinds of conditional medium derived from adipocytes were administered around the basement of the tumors (s.c., $100 \mu \mathrm{l} / 2 \mathrm{~d}$ ) at the start of $5 \mathrm{FU}$ treatment when the tumor diameter was around $0.5 \mathrm{~cm}$. Furthermore, GS antagonist L2A (\#A7275, Sigma, USA), LSD1 inhibitor GSK-LSD1 (\#SML1072, Sigma, USA), and mTOR inhibitor Rapamycin (\#SML2282, Sigma, USA) were also tested in vivo for their ability to interfere with the induction of resistance. L2A ( $1 \mathrm{mg} / \mathrm{kg})$ was administered intraperitoneally every other day for three times. GSK-LSD1 $(0.5$ $\mathrm{mg} / \mathrm{kg}$ ) was administered intraperitoneally every day for 7 days. Rapamycin $(10 \mathrm{mg} / \mathrm{kg})$ was administered intraperitoneally every day for 7 days. Tumor growth was monitored every day by measuring diameters using Vernier caliper. After 18 days after injection, mice were sacrificed followed by dissection and assessment of PC. Then the tumors were calculated in weight.

\section{Metabolomics}

Fat tissues were collected from the peritoneum of the peritoneal metastasis model $(\mathrm{n}=3)$ and the in situ CRC model $(\mathrm{n}=3)$. Fat tissues from peritoneum of WT mice $(n=6)$ and $\mathrm{Tg}^{\mathrm{GS}}$ mice $(\mathrm{n}=$ 6) were also collected. Metabolomics were performed in fat tissues using gas chromatography/time-of-flight mass spectrometry (GC-TOF/MS) measurement (Agilent 7890BLECO Pegasus HT/BT). The Chroma TOF4.3X software (LECO) and LECO-Fiehn Rtx5 database were used for raw peaks extraction, data baselines filtering, and calibration. The resulted three-dimensional data involving the peak number, sample name, and normalized peak area were fed to SIMCA14 software package (Umetrics, Umea, Sweden) for principal component analysis (PCA) and orthogonal projections to latent structures-discriminate analysis (OPLS-DA). The identified differential metabolites (fold change $>2$ or $<0.5, \mathrm{P}<$ $0.05)$ were used to perform heatmap analysis. TBtools software was used to perform heatmaps of differential metabolites (28).

\section{Cell Counting Kit-8 Assay}

The cell viability in 5FU treatment was measured by performing CCK8 assay. The CRC cells including CT26, MC38, SW-480, and HCT-116 cells and melanoma cells B16 were trypsinized and seeded at $1.0 \times 10^{4}$ cells/well in 96-well plates, respectively. After overnight incubation, the medium was removed and replaced with different kinds of conditional medium derived from adipocytes and 5FU $(10 \mu \mathrm{mol} / \mathrm{l})$ for chemotherapy. At different time points, $10 \mu \mathrm{l}$ of CCK8 solution (Dojindo Laboratories, Japan) in PBS was added into each well. Plates were incubated at $37^{\circ} \mathrm{C}$ for another $1 \mathrm{~h}$. The optical density for each well was measured using a microculture plate reader (BioTek, USA) at absorbances of $450 \mathrm{~nm}$.

\section{Cell Cycle Arrest Assay}

Cell cycle arrest assay was performed using a cell cycle assay kit (C1052, Beyotime, China).

Briefly, the CT-26 cells were digested to single cells and washed twice with cold PBS. Then, the cells were fixed with cold ethanol (75\%) for $12 \mathrm{~h}$ and washed with cold PBS. Finally, the cells were stained with propidium iodide for $30 \mathrm{~min}$ before flow cytometry analysis.

\section{Annexin V Apoptosis Assay}

Cell apoptosis assay was performed using Annexin V staining (AO2001-02A-H, Sungene Biotech, China). CT26 cells were trypsinized and seeded at $2.0 \times 10^{5}$ cells/well in six-well plates. After overnight incubation, the medium was removed and replaced with different kinds of conditional medium derived from adipocytes and 5FU $(10 \mu \mathrm{mol} / \mathrm{l})$ for chemotherapy. Each well was added with annexin V-FITC and was incubated at $37^{\circ} \mathrm{C}$ for $15 \mathrm{~min}$ in the dark. The annexin V-FITC binding was detected by flow cytometry (FACSAria, BD Bioscience) using FITC signal detector (FL1) and PI staining by the phycoerythrin emission signal detector (FL2).

\section{Knockdown of Glutamine Synthetase by RNA Interference}

The specific siRNA targeted mouse GS (si-GS: 5'CCACCTCAGCAAGTTCCCACTTGAA- 3') and a scrambled control siRNA that had no sequence homology to any known genes (5' - CCAGACTGAACCCTTTCACTCCGAA - 3') were designed and synthesized by Qiagen (Shanghai, China).

\section{Knockdown of mTORC1 by shRNA}

Plasmid pGCsi-U6-Neo-GFP-shRNA Expression Vector (GeneChem) was used. We designed two pairs of 


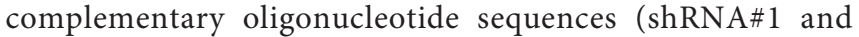
shRNA\#2) according to the cDNA sequences of mTORC1 (GenBank Accession Number: NM_028022.2). The scrambled control plasmid was a circular plasmid encoding a shRNA which had the sequence not present in the mouse, human, or rat genome databases. The sequences are shown below:

shRNA\#1:

5' - CACCGCAGTCGGTGCAAGTTCTTCACGAA T GAAGAACTTGCACCGACTGC -3'

5’ - AAAAGCAGTCGGTGCAAGTTCTTCATTCGTGAAG AACTTGCACCGACTGC -3'

shRNA\#2:

5' - CACCGGTACATCTCCATTGTCATGGCGAACCATGAC AATGGAGATGTACC -3'

5’ - AAAAGGTACATCTCCATTGTCATGGTTCGCCAT GACAATGGAGATGTACC -3’

\section{Real-Time PCR}

Total RNAs were isolated using a peqGold Total RNA Kit including DNase digestion

(Peqlab, Erlangen, Germany). RNAs were transcribed into cDNAs using Omniscript

(Qiagen, Hilden, Germany). qPCR was performed using the 7900 HT Fast Real-Time

PCR system (Applied Biosystems, Darmstadt, Germany). Expression levels were normalized to $\beta$-actin. Reactions were done in duplicate using Applied Biosystems Taqman Gene Expression Assays and Universal PCR Master Mix. The relative expression was calculated by the 2 (-DDCt) method. The primers are shown as follows:

\section{GLS: Forward TTCGCCCTCGGAGATCCTAC}

Reverse CCAAGCTAGGTAACAGACCCT

GS: Forward CTGAGTGGAACTTTGATGGCT

Reverse GGAAGGGGTCTCGAAACATGG

SLC1A5: Forward CATCAACGACTCTGTTGTAGACC

Reverse CTGGATACAGGATTGCGGTATTT

SLC7A5: Forward CTACGCCTACATGCTGGAGG

Reverse GAGGGCCGAATGATGAGCAG

\section{Western Blotting Assays}

Cell extracts were prepared according to the instruction of RIPA buffer (Biotek Corporation, Beijing, China). Cell lysates were collected by centrifugation at $12,000 \mathrm{rpm}$ for $15 \mathrm{~min}$ at $4^{\circ} \mathrm{C}$, and then transferred to clean microcentrifuge tubes. Protein concentration was determined with Bradford reagent (BioRad), and equal amounts of proteins $(60 \mu \mathrm{g})$ were run on a 10 or $15 \%$ SDS-PAGE gel and blotted onto polyvinylidene fluoride membranes. After blocking for $1 \mathrm{~h}$ at room temperature with 5\% non-fat dry milk, membranes were incubated with primary antibodies mouse anti-GS antibody (1:100, \#ab64613, Abcam, USA), rabbit anti-H3k4me2 (1:1,000, \#9725S, Cell Signaling Technology, USA), rabbit anti-LSD1 (1:1,000, \#2139S, Cell
Signaling Technology, USA), rabbit anti-p-mTOR (Ser2448) (1:1,000, \#9964T, Cell Signaling Technology, USA), rabbit antimTOR (1:1,000, \#9964T, Cell Signaling Technology, USA), rabbit anti-mTORC1 (1:1,000, \#9964T, Cell Signaling Technology, USA), rabbit anti-tubulin $(1: 1,000$, \#2146S, Cell Signaling Technology, USA), rabbit anti- $\beta$-actin antibody (1:1,000, \#8457S, Cell Signaling Technology, USA), or rabbit anti-LaminB (1:1,000, \#12255S, Cell Signaling technology, USA) at $4^{\circ} \mathrm{C}$ overnight, respectively. After rinsed with TBST, the membranes were incubated with HRP-conjugated secondary antibodies goat anti-rabbit (1:2,000, \#ZB-2301, ZSGB, China) and goat anti-mouse (1:2,000, \#ZB-2305, ZSGB, China). The signals were stimulated with Enhanced Chemiluminescence Substrate (\#NEL105001 EA, PerkinElmer) for $1 \mathrm{~min}$ and captured with a Bio-Rad ChemiDoc MP System (170-8280).

\section{Hematoxylin and Eosin Staining}

Adipose tissue, kidneys, spleens, and livers were collected from mice. These tissues were fixed in $10 \%$ buffered formalin for $48 \mathrm{~h}$ and immersed in $30 \%$ sucrose for $48 \mathrm{~h}$. The tissues were then cut into sections at an interval of $30 \mu \mathrm{m}$. The sections were then deparaffinized, hydrated, washed, and stained with hematoxylin and eosin $(\mathrm{H} \& \mathrm{E})$ staining. Images were taken under a light microscope (Leica, Germany).

\section{Calculation of Inhibition Rates by $5 \mathrm{FU}$ In Vitro and In Vivo}

The cell viability was measured according to CCK8 assays. The cell growth curve of each group was displayed in the observed time period. The inhibition rate by $5 \mathrm{FU}$ was obtained by calculating the percentage of 5FU-reduced area under the curve in the observed time period. For example, the inhibition rate of NM group in Figure 1B was obtained by calculating the reduced-percentage of area (between the NM curve and NM+ $5 \mathrm{FU}$ curve) relative to the area under the NM curve in the observed time period in Figure 1A. In vivo, the tumor growth curve of each group was recorded. Likewise, the inhibition rate by $5 \mathrm{FU}$ was calculated as describe above.

\section{Statistical Analysis}

For in vitro and in vivo results and metabolome data, statistical analysis was analyzed using SPSS 17.0 software (Version 17.0, LEAD Technologies, Chicago, USA). These data were expressed as mean \pm SEM. Two-tailed unpaired Student's t-test was utilized to analyze data between two groups. One-way ANOVA was used to analyze data among three groups with Turkey's post hoc analysis. ${ }^{\star} P<0.05$. ${ }^{\star \star} P<0.01$. ${ }^{\star \star \star} P<0.001$.

\section{RESULTS}

\section{Adipocytes Resist 5FU Efficacy in CRC Treatment}

To explore the mechanism linking adipocytes to 5FU efficiency, we first collected the conditional medium (CM) of adipocytes differentiated from 3T3-L1 cells to treat the mouse CRC cells 
A

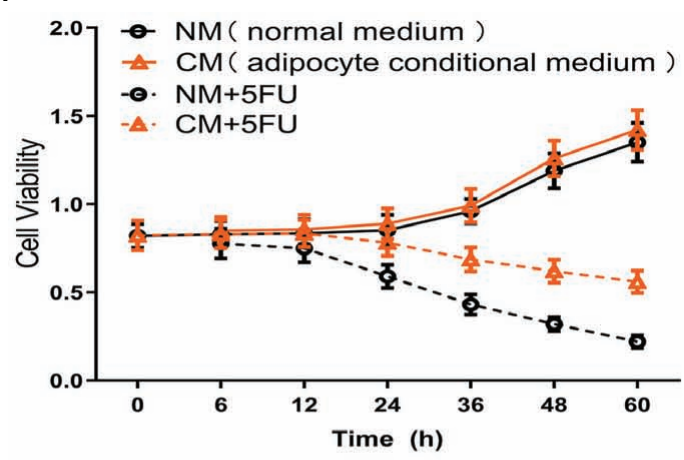

C

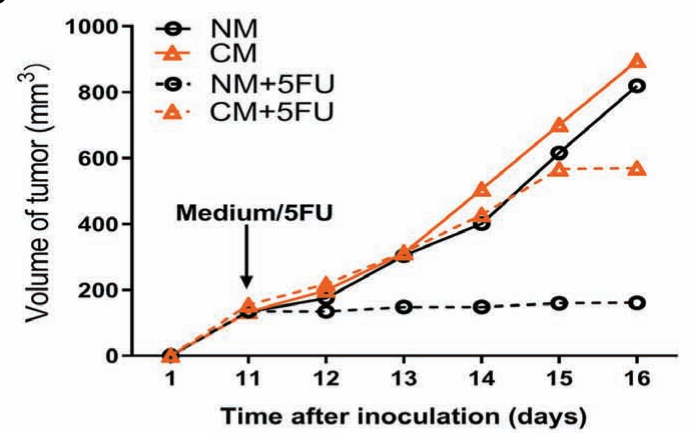

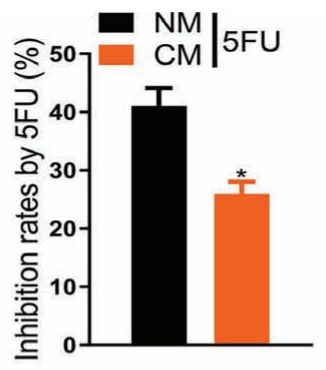

D

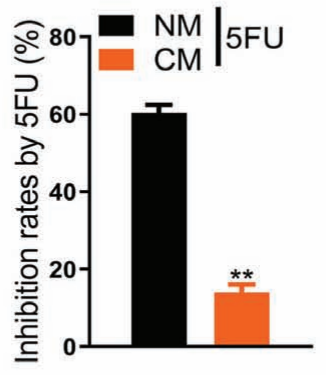

E

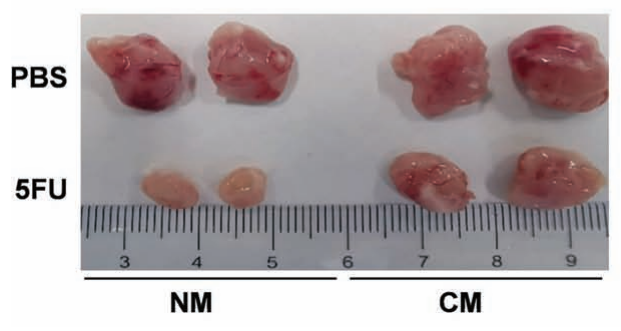

$\mathbf{F}$

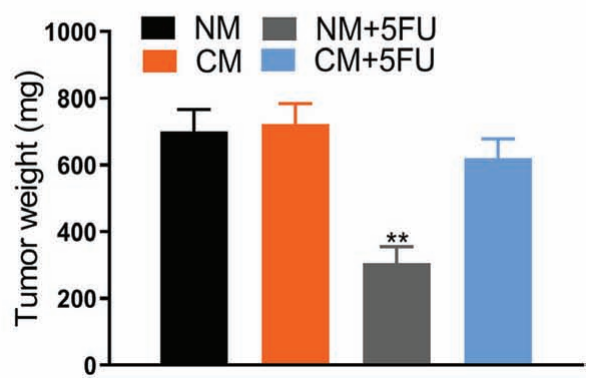

FIGURE 1 | Adipose cells resist 5FU efficacy in CRC treatment. (A) Cell viability of CT26 cells treated with conditional medium and $5 F U$ (10 $\mu$ mol/L) by CCK8 assays $(n=5)$. (B) The inhibition rates of 5FU were measured according to (A) $\left(n=5,{ }^{*} P<0.05\right)$. (C) Adipose cells induce resistance of CT26-tumors to 5FU treatment. CT26 cells $\left(1.0 \times 10^{6}\right)$ were subcutaneously implanted in BALB/C mice. The treatment with 5FU and/or the conditional medium including NM, CM, and $\mathrm{CM}(5 \mathrm{FU})$ was initiated when the tumor size reached to around $0.5 \mathrm{~cm}$ in diameter. The tumor size was measured dynamically. (D) The inhibition rates based on (C) were calculated $\left(n=5,{ }^{*} P<0.01\right)$. (E) The representative images of CT26 tumors (on day 17) from the mice as described in (C). (F) Weight of CT26 tumors (on day 17) from the mice as described in (C) $\left(n=5,{ }^{\star \star} P<0.01\right)$.

(CT26 cells) undergoing 5FU treatment. We showed that CM, but not normal medium (NM), notably weakened 5FU-induced proliferation inhibition of CT26 cells (Figures 1A, B). In mouse xenograft models, the inhibitory effect of 5FU on CT26-tumor size was largely blocked by CM (Figures 1C, D). Tumor weight reduced by $5 \mathrm{FU}$ was also rescued by $\mathrm{CM}$ (Figures 1E, F). Moreover, the effect of $\mathrm{CM}$ on 5FU resistance was confirmed by cell viability in human CRC cells like HCT-116 (Figures S1A, B) and SW-480 (Figures S1C, D). Cell cycle arrest assay showed that CM or 5FU did not affect cell cycle of CT26 cells. Whereas, Annexin $\mathrm{V}$ apoptosis assay showed that CM reversed the stimulatory effect of 5FU on apoptosis (Figures S1E, F). These results suggest that adipocytes induce chemoresistance to $5 \mathrm{FU}$ treatment for CRC.

\section{Adipocyte-Derived Glutamine Promotes Resistance to 5FU Chemotherapy}

Dysfunctional adipocytes can secrete cytokines and metabolites, promoting proliferation, progression, and migration of cancer cells (29). To explore which factors from adipocytes are involved in chemoresistance to 5FU, we separated the $\mathrm{CM}$ of adipocytes into two fractions: cytokine fraction $(>3 \mathrm{kD})$ and metabolite fraction 
$(<3 \mathrm{kD})$. The inhibition rate by $5 \mathrm{FU}$ in CT26 cells was significantly reduced by metabolite fraction $(<3 \mathrm{kD})$ rather than cytokine fraction $(>3 \mathrm{kD}$ ) (Figures 2A, B). Then, we performed metabolomics analysis of fat tissues from the peritoneum of the peritoneal metastasis model and the in situ CRC model. We found that the Gln level was markedly increased in fat tissues in the CRCPC model compared with the in situ CRC model (Figure 2C), indicating that Gln might induce chemoresistance to 5FU therapy, leading to PC. To verify this hypothesis, we tested the cell viability of CT26 cells treated with Gln or PBS. The data showed that Gln resisted 5FU-induced cell growth inhibition in CT26 cells (Figures 2D, E). In addition, the tumor weight was increased in Gln-treated intraperitoneal xenografts compared with PBS-treated intraperitoneal xenografts under the treatment of 5FU (Figure 2F), demonstrating the desensitizing effect of Gln on 5FU therapy. Moreover, we also verified that Gln induced resistance to 5FU chemotherapy in human CRC cells SW-480 (Figures S2A, B) and
HCT-116 (Figures S2C, D). In mouse subcutaneous xenograft models, the 5FU-reduced tumor weight was rescued by Gln, while Gln alone did not affect tumor weight (Figures S2E, F).

\section{Adipocytic Gln Synthetase Promotes Chemoresistance to 5FU Therapy in CRC-PC}

Given that Gln level can be regulated by enzymes GS and glutaminase (GLS) and amino acid transporters SLC1A5 and SLC7A5 (30), and that cancers cause dysregulation of GS and GLS (16), we detected relative mRNA levels of GLS, GS, SLC1A5, and SLC7A5 in fat tissues of mice with CRC or those of mice with CRC-PC by qPCR to evaluate the changes of Gln metabolism in CRC-PC. We found that GS expression was higher in the fat tissue from the peritoneum of the CRC-PC model compared with the in situ CRC model, while the expressions of GLS, SLC1A5, and SLC7A5 did not differ between
A
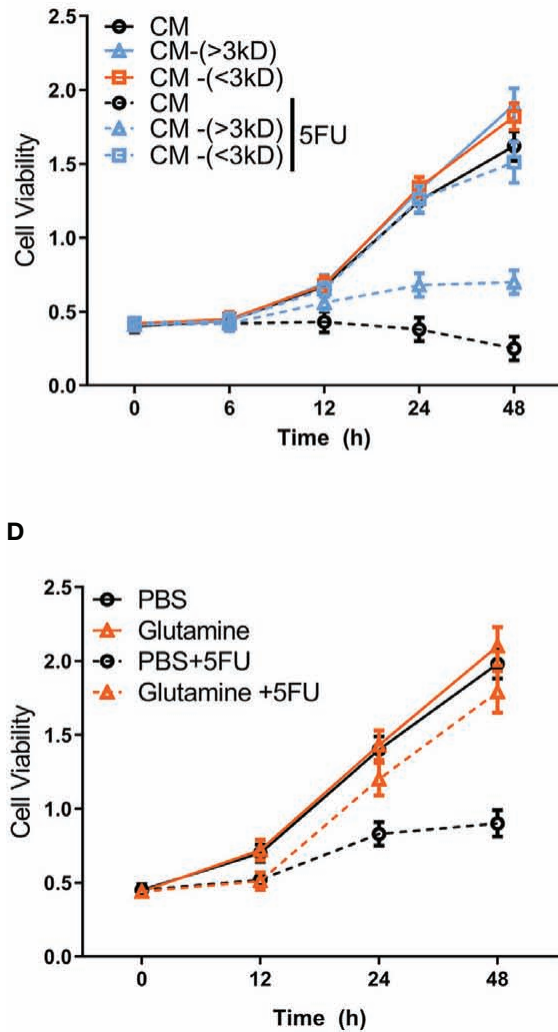

B
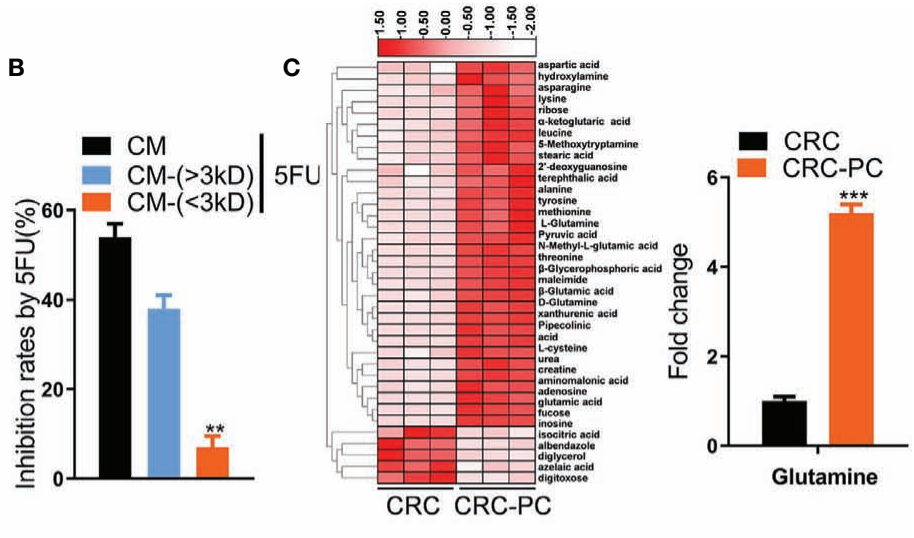

E

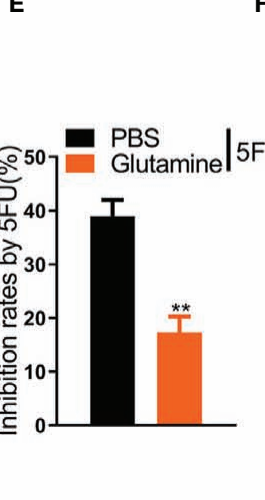

$\mathbf{F}$

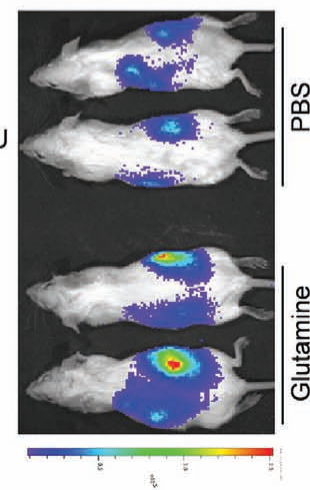

œ̊n

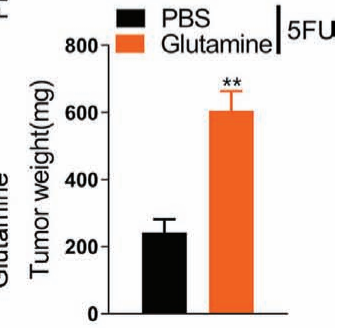

FIGURE 2 | Adipocyte-derived glutamine (GIn) promotes resistance to 5FU chemotherapy in mouse CRC cells. (A) CM was separated into two fractions based on size: $\mathrm{CM}-(<3 \mathrm{KD})$ and $\mathrm{CM}-(>3 \mathrm{KD})$. The cell viability of $\mathrm{CT} 26$ cells treated with $\mathrm{CM}, \mathrm{CM}-(<3 \mathrm{KD})$ or $\mathrm{CM}-(>3 \mathrm{KD})$ plus with/without $5 \mathrm{FU}(10 \mu \mathrm{mol} / \mathrm{L})$ was measured. (B) The growth inhibition rates by $5 F U$ were calculated according to (A) $\left(n=5,{ }^{\star \star} P<0.01\right)$. (C) Left, heatmap showing differential metabolic profiles of fat tissues from the peritoneum of the in situ CRC mode (CRC) $(n=3)$ and the peritoneal metastasis model (CRC-PC) $(n=3)$. The color represents the metabolite concentration of each sample calculated by peak area normalization method. Right, fold change of Gln level between the CRC-PC and the CRC group $\left(n=3,{ }^{* \star *} P<0.001\right)$. (D) Cell viability of CT26 cells treated with 5FU (10 $\mu \mathrm{mol} / \mathrm{L})$, Gln $(2 \mathrm{mM})$ or Gln $(2 \mathrm{mM})$ plus $5 \mathrm{FU}(10 \mu \mathrm{mol} / \mathrm{L})$. (E) Inhibition rates by $5 \mathrm{FU}$ according to the data in (D) $(\mathrm{n}=$ $\left.5,{ }^{\star *} P<0.01\right)$. (F) Gln-induced chemoresistance to 5FU. Left, tumor growth in peritoneal xenografts. Right, tumor weight. The tumors were isolated and weighed on day $17\left(n=5,{ }^{*} P<0.01\right)$ 
the two groups (Figure 3A). We also detected the relative protein levels of GS by Western blot. In accordance with the mRNA level, the relative protein level was increased in the fat tissue from the peritoneum of the CRC-PC model compared with the in situ CRC model (Figures 3B, C). Next, we generated adipocyte-specific GSexpressing transgenic mice $\left(\mathrm{Tg}^{\mathrm{GS}}\right)$ and verified increased protein and mRNA levels of GS in $\mathrm{Tg}^{\mathrm{GS}}$ mice compared with WT mice (Figures S3A, B). We also verified an increase in adipose-specific GS mRNA levels (Figure S3C). H\&E staining of adipose, kidney, spleen, and liver showed no apparent difference between WT and Tg ${ }^{\mathrm{GS}}$ mice (Figure S3D). Next, we established xenograft models in $\mathrm{Tg}^{\mathrm{GS}}$ mice. The inhibition rates by $5 \mathrm{FU}$ showed no difference between 5FU-treated WT mice and 5FU-treated $\mathrm{Tg}^{\mathrm{GS}}$ mice (Figures 3D, E). WT mice and $\mathrm{Tg}^{\mathrm{GS}}$ mice were intraperitoneally inoculated with MC38 cells and treated with PBS or 5FU for 2 weeks. The tumor weight was reduced in 5FU-treated WT mice compared with non-treated WT mice, whereas 5FU-treated $\mathrm{Tg}^{\mathrm{GS}}$ mice showed no difference with non-treated $\mathrm{Tg}^{\mathrm{GS}}$ mice in tumor weight (Figures 3F, G). L2A, an antagonist of GS, was given to 5FU-treated $\mathrm{Tg}^{\mathrm{GS}}$ mice. We found that the tumor growth was reduced in $\mathrm{L} 2 \mathrm{~A}+5 \mathrm{FU}$-treated $\mathrm{Tg}^{\mathrm{GS}}$ mice compared with $5 \mathrm{FU}$ treated $\mathrm{Tg}^{\mathrm{GS}}$ mice (Figure $\mathbf{3 H}$ ). Further, GS was silenced by siRNA in adipocytes differentiated from 3T3-L1 cells, which was verified by the decreased GS mRNA level in si-GS-treated cells compared with si-NC-treated mice (Figure S4A). As expected, siGS also reduced the relative glutamine level compared with si-NC (Figure S4B). In addition, CM from si-GS-treated adipocytes significantly increased 5FU-induced growth inhibition of CT26 cells compared with CM from si-NC-treated adipocytes (Figure S4C). The inhibition rates by $5 \mathrm{FU}$ were also reserved by $\mathrm{CM}$ from si-GS-treated adipocytes (Figure S4D). In mouse xenograft models, the resistance to $5 \mathrm{FU}$ on CT26 tumor weight was reversed by CM (si-GS) (Figure S4E). Those results indicate that adipocytic GS induces chemoresistance to 5FU treatment for CRC-PC.
A

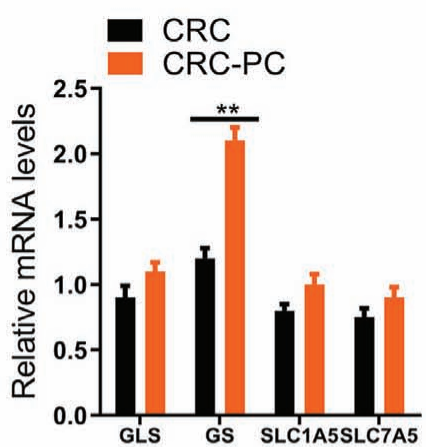

$\mathbf{F}$

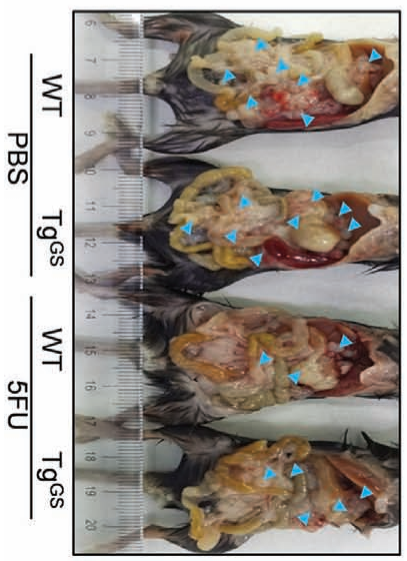

B
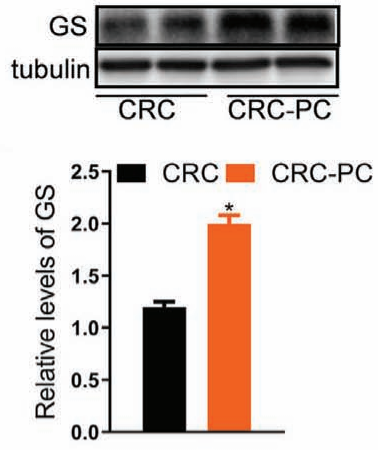

D

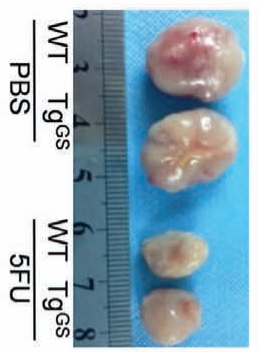

E

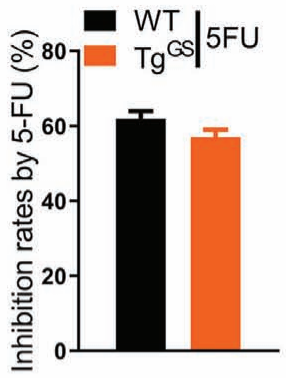

G

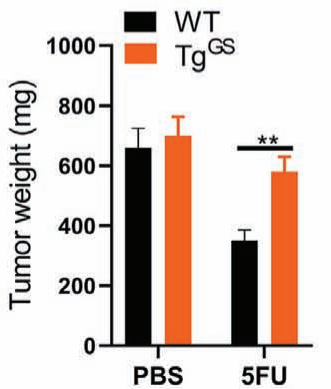

H

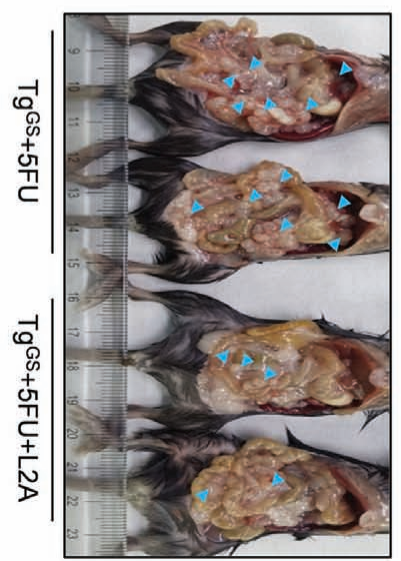

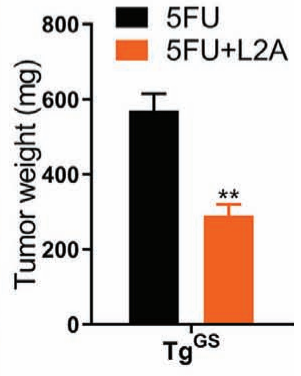

FIGURE 3 | Adipocytic glutamine synthetase (GS) promotes chemoresistance to 5FU therapy in CRC-PC. (A) qPCR detecting relative mRNA levels of GLS, GS, SLC1A5, SLC7A5 in fat tissues from the peritoneum of the CRC model $(n=3)$ and CRC-PC $(n=3){ }^{* *} P<0.01$. (B) The protein levels of GS in the CRC-PC model and the CRC model were measured with Western blot. (C) The relative protein levels of GS in (B) were calculated $\left(n=3,{ }^{*} P<0.05\right)$. (D) The representative images of MC38 tumors (on day 17) from the PBS-treated WT and GS transgenic ( $\mathrm{Tg}^{\mathrm{GS}}$ ) mice, 5FU-treated WT and $\mathrm{Tg}^{\mathrm{GS}}$ mice. (E) The growth inhibition rates by $5 \mathrm{FU}$ in WT and $\mathrm{Tg}^{\mathrm{GS}}$ mice $(\mathrm{n}=5)$. (F) WT mice and Tg ${ }^{\mathrm{GS}}$ mice were intraperitoneally inoculated with MC38 cells, and treated with PBS or $5 \mathrm{FU}$ for 2 weeks, respectively. Then, the representative images of the mice-bearing tumors were showed. Arrow heads, tumors. (G) The tumors in $\mathbf{( F )}$ were isolated and weighed $\left(\mathrm{n}=3\right.$, $\left.{ }^{\star \star} P<0.01\right)$. (H) Left, $\mathrm{Tg}^{\mathrm{GS}}$ mice were intraperitoneally inoculated with MC38 cells, and treated with $5 \mathrm{FU}$ or $5 \mathrm{FU}+\mathrm{L} 2 \mathrm{~A}$, respectively. Arrow heads, tumors. Right, the tumors were isolated and weighed $\left(\mathrm{n}=3,{ }^{\star \star} P<0.01\right)$. 


\section{Loss of H3k4me2 Increases GS Expression in Adipose Cells}

To detect metabolite changes induced by GS overexpression, we collected fat tissue samples from WT mice and $\mathrm{Tg}^{\mathrm{GS}}$ mice and performed metabolomics. OPLS-DA score was calculated for each sample (Figure S5A), and differential metabolites of samples from WT mice and $\mathrm{Tg}^{\mathrm{GS}}$ mice are shown in Figure S5B. The metabolomic data showed differentially expressed amino acid metabolites associated with the methionine cycle including methionine (Met), cysteine (Cys), S-carboxymethyl-Lcysteine, S-Adenosyl methionine (SAM), and adenosine (fold change $>2, P<0.05$ ) (Figure 4A). In the methionine cycle, Met is converted to SAM, the donor for epigenetic methylation, via methionine adenosyl-transferase. The methyl group is transferred to S-carboxymethyl-L-cysteine from SAM via methyltransferase (Figure 4B). SAM also provides methyl groups for DNA histone methylation (31). To explore the influence of CRC or 5FU treatment on histone methylation, we evaluated the expressions of several common histone methylation markers $\mathrm{H} 3 \mathrm{~K} 4 \mathrm{me} 2, \mathrm{H} 3 \mathrm{~K} 4 \mathrm{me} 3$, H3K9me2, $\mathrm{H} 3 \mathrm{~K} 27 \mathrm{me}$, and H3K79me2 by Western blot in mouse adipose cells in vitro. The expression of $\mathrm{H} 3 \mathrm{k} 4 \mathrm{me} 2$, dimethylation at lysine 4 of histone $\mathrm{H} 3$, was reduced in mouse adipose cells cultured with CT26 cell supernatants compared with ones cultured with NM, while the expression of $\mathrm{H} 3$ did not differ between CT26 cell supernatant-treated adipocytes and NMtreated adipocytes (Figure $\mathbf{4 C}$ ). LSD1 is a histone H3k4me2 demethylase, and we measured the expression of LSD1 in mouse adipocytes by Western blot. As expected, the expression of LSD1 was increased in adipocytes cultured with CT26 cell supernatants compared with ones cultured with NM. H3k27me2, dimethylation at lysine 27 of histone $\mathrm{H} 3$, showed reduced expression under 5FU treatment but no apparent difference in expressions when cultured with CT26 supernatants or NM (Figure S5C). The expressions of $\mathrm{H} 3 \mathrm{k} 4 \mathrm{me} 3, \mathrm{H} 3 \mathrm{k} 9 \mathrm{me} 2$, and H3k79me2 were affected by neither 5FU treatment nor CT26 supernatants. As expected, the expression of GS was increased in mouse adipose cells cultured with CT26 cell supernatants compared with adipose cells cultured with NM under the treatment of 5FU or non-treatment. GSK-LSD1 is a potent inhibitor of LSD1 and the inhibitory effect of GSK-LSD1 was confirmed by Western blot. Under the treatment of GSK-LSD1, the $\mathrm{H} 3 \mathrm{k} 4 \mathrm{me} 2$ expression was increased and the GS expression in adipocytes was reduced in a dose-dependent manner

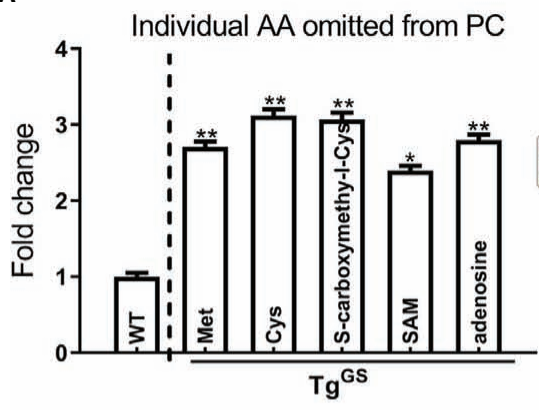

D

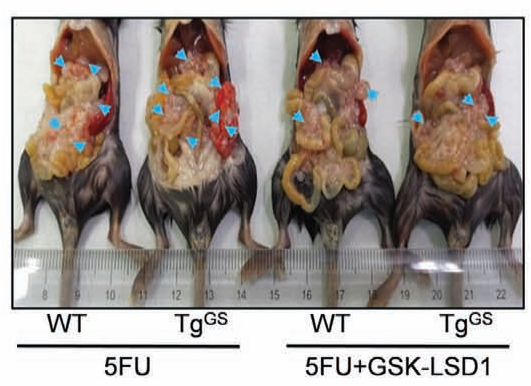

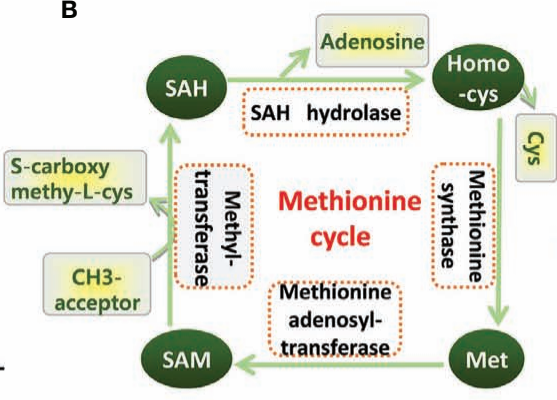

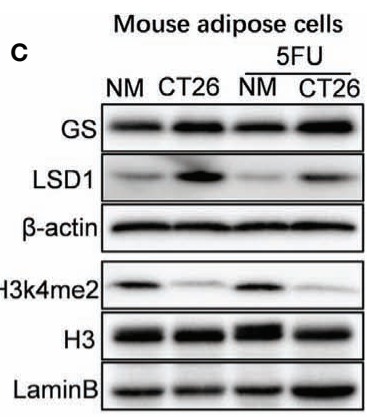

E

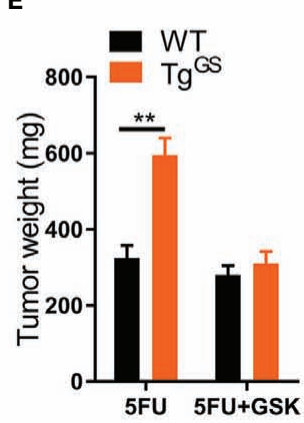

$\mathbf{F}$

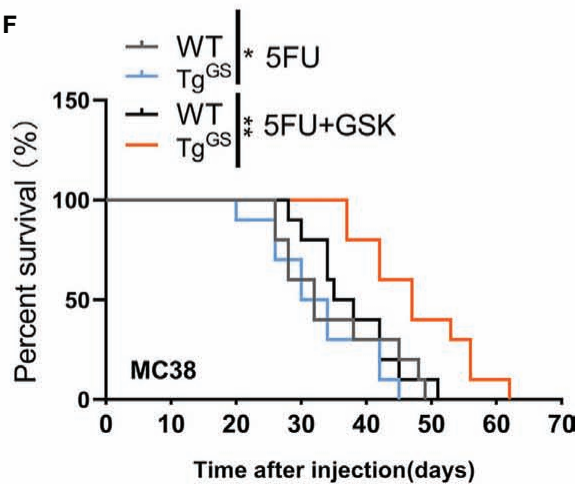

FIGURE 4 | Loss of H3K4me2 increases GS expression in adipose cells. (A) Fold change of individual amino acid (AA) omitted from PC of WT and Tg GS mice ( $\mathrm{n}=3$, ${ }^{\star} P<0.05$, ${ }^{\star \star} P<0.01$ ). (B) Schematic diagram of methionine cycle. (C) The protein levels of GS, LSD1, H3K4me2, and H3 in non-treated or 5FU-treated mouse adipose cells cultured with NM or CT26 cell supernatants were measured with Western blot. (D) WT mice and Tg ${ }^{\text {GS }}$ mice were intraperitoneally inoculated with MC38 cells and treated with 5FU or 5FU+GSK-LSD1 for 2 weeks, respectively. Then, the representative images of the mic-bearing tumors were showed. Arrow heads, tumors. (E) The tumors in (D) were isolated and weighed ( $n=5$, $\left.{ }^{\star \star} P<0.01\right)$. (F) Kaplan-Meier curves for the survival of 5FU-treated or 5FU+GSK-LSD1treated WT mice or TG ${ }^{G S}$ mice after MC38 tumor cell inoculation plotted against time (days after injection) $\left(\mathrm{n}=10,{ }^{\star \star} P<0.01\right)$. 
(Figure S5D). GSK-LSD1 also reduced the secretion of Gln in the supernatant of CT26 cells (Figure S5E). Furthermore, we demonstrated that the supernatant from MC38 suppressed expression of $\mathrm{H} 3 \mathrm{k} 4 \mathrm{me} 2$ in adipocytes, and this effect was rescued by GSK-LSD1 (Figure S5F). To evaluate the effect of $\mathrm{H} 3 \mathrm{k} 4 \mathrm{me} 2$ on GS-induced chemoresistance to $5 \mathrm{FU}$, we administered GSK-LSD1 to tumor xenograft $\mathrm{Tg}^{\mathrm{GS}}$ mice and treated the mice with 5FU. Under the treatment of 5FU, the tumor weight of tumor xenograft $\mathrm{Tg}^{\mathrm{GS}}$ mice was increased compared with WT mice, indicating GS-induced resistance to 5FU treatment. After administrating GSK-LSD1, the effect of GS on drug resistance was blocked (Figures 4D, E). In addition, after MC38 tumor cell inoculation, Tg ${ }^{\mathrm{GS}}$ mice with $5 \mathrm{FU}+\mathrm{GSK}$ LSD1 treatment showed better survival than $\mathrm{Tg}^{\mathrm{GS}}$ mice with $5 \mathrm{FU}$ treatment (Figure 4F). Those results suggest that loss of $\mathrm{H} 3 \mathrm{k} 4 \mathrm{me} 2$ increases GS expression and GS-induced chemoresistance to 5FU therapy for CRC.

\section{Tumor Cells Outcompete Adipose Cells for Gln via mTORC1}

Amino acid metabolism has been shown to participate in mTOR signaling $(32,33)$. To detect whether mTOR signaling is involved in adipocyte and GS-induced chemoresistance of CRC to 5FU, we established co-culture models of adipocytes and CRC tumor cells using mouse adipocytes differentiated from 3T3-L1 cells $\mathrm{AD}$ cocultured with mouse tumor cell lines B16, CT26, and MC38, respectively. Then we utilized Western blot to measure relative protein levels of mTOR and p-mTOR. In the co-culture system, the relative protein level of p-mTOR (Ser2448) was higher in B16 cells, CT26 cells, and MC38 cells than in AD cells (Figures 5A, B), indicating that mTOR activation is increased in tumor cells. Furthermore, the expression of GS was increased in fat tissue of peritoneal in the CRC-PC model compared with that in the CRC model, while the expression of $\mathrm{H} 3 \mathrm{k} 4 \mathrm{me} 2$ was reduced in mice with CRC-PC compared mice with in situ CRC, p-mTOR no apparent difference in expressions (Figure S6A). To detect which of the two multi-protein complexes mTORC1 and MTORC2 has an effect on CRC cell survival, we added regulatory-associated protein of mTOR (Raptor) or rapamycin-insensitive companion of mTOR (Rictor), the component of mTORC1 and mTORC2, respectively (34), to CT26 cells. We found that Raptor, but not Rictor, inhibited survival rate of CT26 cells (Figure S6B). Then we knocked down mTORC1 by shRNA and verified it using Western blot (Figure S6C). The survival rate of CT26 cells was inhibited by mTORC1 shRNAs (Figure S6D). Moreover, tumor growth was also inhibited by mTORC1 shRNAs in mouse xenograft models (Figures S6E, F). Rapamycin, a selective mTOR inhibitor, was added to CM-treated CT26 cells for detecting whether mTOR was involved in chemoresistance to 5FU treatment. We found that the combined treatment of 5FU+Rapamycin had a stronger inhibitory effect on CT26 cell proliferation than 5FU treatment alone (Figure 5C), indicating that mTOR activation mediates resistance to $5 \mathrm{FU}$ therapy for CRC. Further, mouse tumor xenograft models were established in $\mathrm{Tg}^{\mathrm{GS}}$ mice (Figure 5D). 5FU+Rypamycin reduced the tumor weight of xenograft $\mathrm{Tg}^{\mathrm{GS}}$ mice compared with $5 \mathrm{FU}$ treatment alone (Figure 5E). In addition, after MC38 tumor cell inoculation, Tg ${ }^{\mathrm{GS}}$ mice with 5FU+Rapamycin treatment showed better survival than $\mathrm{Tg}^{\mathrm{GS}}$ mice with 5FU treatment (Figure 5F). These results suggest that mTOR activation mediated GS-induced chemoresistance to 5FU therapy for CRC.

\section{DISCUSSION}

Our present study reveals a novel mechanism of chemoresistance of CRC-PC to 5FU therapy. In the TME of CRC-PC, tumor cells outcompete adipocytes for Gln, leading to Gln deficiency. We show that this change in the TME induces GS upregulation in adipocytes, increasing the production of Gln, which promotes resistance of tumor cells to 5FU chemotherapy, a process mediated by mTOR activation. We also show that abnormal methionine metabolism in adipocytes may lead to altered H3k4me2 expression, which contributes to GS upregulation and chemoresistance to 5FU (Figure 6).

TME is a potential therapeutic target for metastasis and drug resistance $(35,36)$. TME consists of different cell types surrounding tumor cells, including fibroblasts, immune cells, endothelial cells, and adipocytes. The diversity of phenotypes in TME components may contribute to resistance to some therapies (36). Among TME components, adipocytes play an active role in chemoresistance. In ovarian cancer cells with adipocyte co-culture, adipocyte-induced demethylation reprograms cancer cell metabolism and promotes resistance to chemotherapy (37). In vivo studies have reported that adipocytes promote the metastasis of breast cancer $(38,39)$. In the current study, we displayed the pivotal role of adipocytes in promoting resistance to 5FU chemotherapy for CRC-PC. Some possible mechanisms underlying adipocytes-induced peritoneal metastasis include induction of angiogenesis via the CXCL2VEGFA axis (40), activation of the PI3K/AKT/mTOR pathway by producing MCP-1 (41), upregulation of CD36 in tumor cells (42), and fatty acid metabolic reprogramming (43). Adipocytes also play key a role in drug resistance. The underlying mechanisms may include adipose hypoxia (44), alteration of pharmacokinetics $(45,46)$, variation of metabolic program $(47,48)$, production of tumorpromoting growth factors and cytokines (45), enhancement of cancer fibrosis (49), change of microbiota (50), generation of drugresistant cancer stem cells (42), and cell-matrix adherence (51). Here we show a potential mechanism related to Gln metabolism.

Gln, the most abundant free amino acid in the human body, plays essential roles in various metabolic pathways and is involved in mitochondrial dysfunction and tumor cell proliferation (52). Gln metabolism is reprogrammed and plays an essential role in cancer (53). Alternations in amino acid metabolism in cancer result from increased nutritional demands of tumor cells for energy (54). In the present study, CRC cells outcompete adipocytes for Gln, thereby inducing adipocytes producing more Gln. We show that Gln is higher in fat tissue of patients with CRC-PC than in that of patients with CRC, suggesting the role of Gln in cancer metastasis. In human colon cancer cell lines, Gln promotes proliferation and inhibits differentiation, inducing a more aggressive phenotype (55). In the present study, we also demonstrated the desensitizing effect 
A

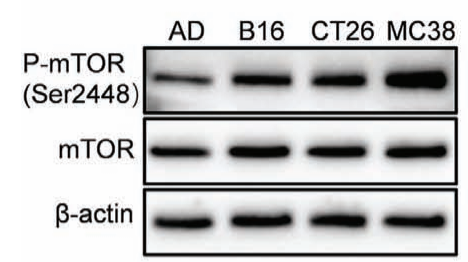

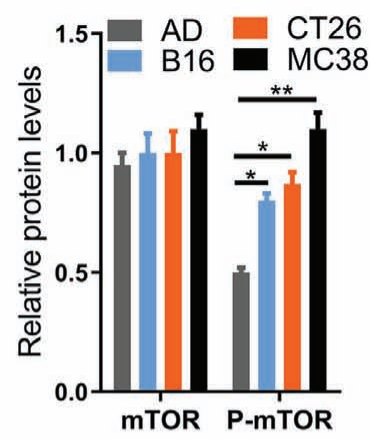

C

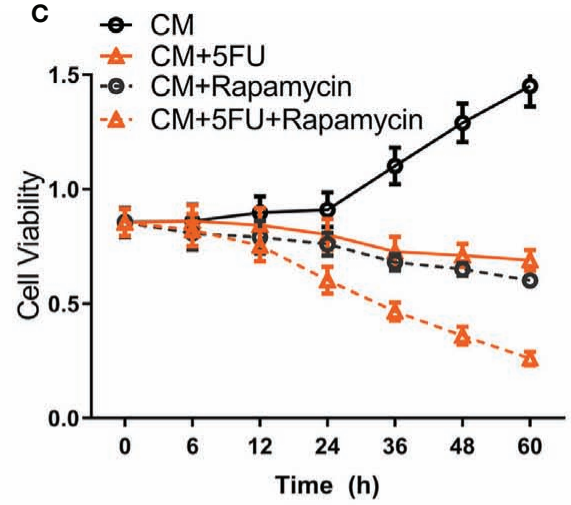

$\mathbf{F}$

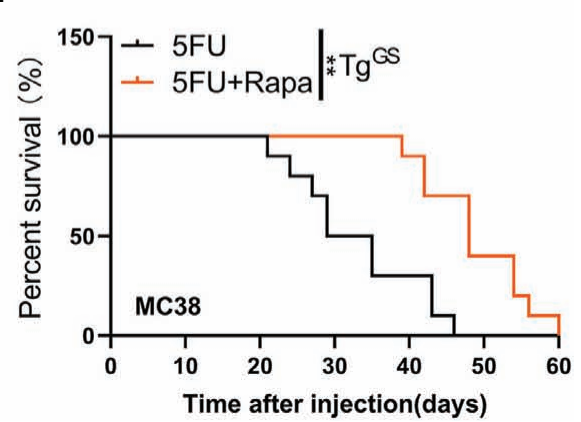

FIGURE 5 | Tumor cells outcompete adipose cells for glutamine via mTORC1. (A) The protein levels of mTOR and p-mTOR (ser2448) in AD, B16, CT26, and MC38 cells were measured with Western blot. (B) The relative protein levels of mTOR and p-mTOR in (B) were calculated $\left(n=3,{ }^{*} P<0.05,{ }^{\star \star} P<0.01\right)$. (C) Cell viability of CT26 cells treated with CM CM+5FU (10 umol/L), CM+Rapamycin, or CM+5FU+Rapamycin by CCK8 assays $(n=5)$. (D) Mice were intraperitoneally inoculated with CT26 cells which were treated with 5FU, Rapamycin, or 5FU+Rapamycin, respectively. Then, the representative images of the mice-bearing tumors were shown. Arrow heads, tumors. (E) The tumors in (D) were isolated and weighed $\left(n=5,{ }^{\star *} P<0.01\right)$. (F) Kaplan-Meier curves for the survival of $5 F U$-treated or $5 F U+$ Rapamycin -treated TGGS mice after MC38 tumor cell inoculation plotted against time (days after injection) $\left({ }^{\star *} P<0.01\right)$.

of Gln on 5FU treatment in mouse xenograft models. Drug resistance has been shown to be associated with amino acid metabolism (54), and Gln metabolism participates in resistance to chemotherapy in CRC (56).

GS is an ATP-dependent metalloenzyme that converts glutamate and ammonia to Gln. GS also contributes to endothelial cell motility and migration, promoting pathological angiogenesis (57). An increasing number of studies have revealed important roles of GS in cancers. The expression of GS was shown to be increased in liver, skeletal muscle, and kidney of rats implanted subcutaneously with fibrosarcoma $(58,59)$. GS overexpression was detected also in human primary liver cancers (60). Resistant hepatoma cell lines have more GS expression than sensitive cell lines (61). GS protein and mRNA levels were also increased in human breast cancer cell lines (62). Genetic deletion of macrophagic GS in tumor-bearing mice inhibited tumor metastasis (63). The current study shows that the protein level and mRNA level of GS are increased in fat tissue of patients with CRC-PC compared with that of patients with CRC. In addition, we displayed the stimulatory effects of GS on chemoresistance to 5FU therapy in mouse xenograft models.
Further, our study revealed a mechanism of adipocytic GSinduced chemoresistance in CRC-PC via mTOR activation, in accordance with a precious study showing that Gln-dependent mTOR activation promotes chemoresistance in pancreatic cancer cells in vitro and in vivo (15). Amino acids can signal to mTORC1 and are the most crucial factors for mTORC1 activation $(64,65)$, but the mechanism remains largely unknown.

Alterations in histone methylation have a global influence on drug resistance in ovarian cancer cells $(66,67)$. In the present study, reduction of histone $\mathrm{H} 3 \mathrm{k} 4 \mathrm{me} 2$ methylation was observed in CRC cells and attributed to GS-induced chemoresistance to 5FU therapy, in accordance with a previous study which showed that H3k4me2 demethylation played an important role in CRC progression (68). In gastric cancer, LSD1 specifically catalyzed the demethylation of mono- and di-methylated H3k4me2, participating in many pathological processes of cancer, including proliferation, apoptosis, and metastasis (69). Overexpression of LSD1 has been proved in numerous cancers, and high level of LSD1 causes tumor aggressiveness and poor prognosis. Previous studies have also shown the synergistic antitumor effect of 5FU with the novel LSD1 inhibitor in 


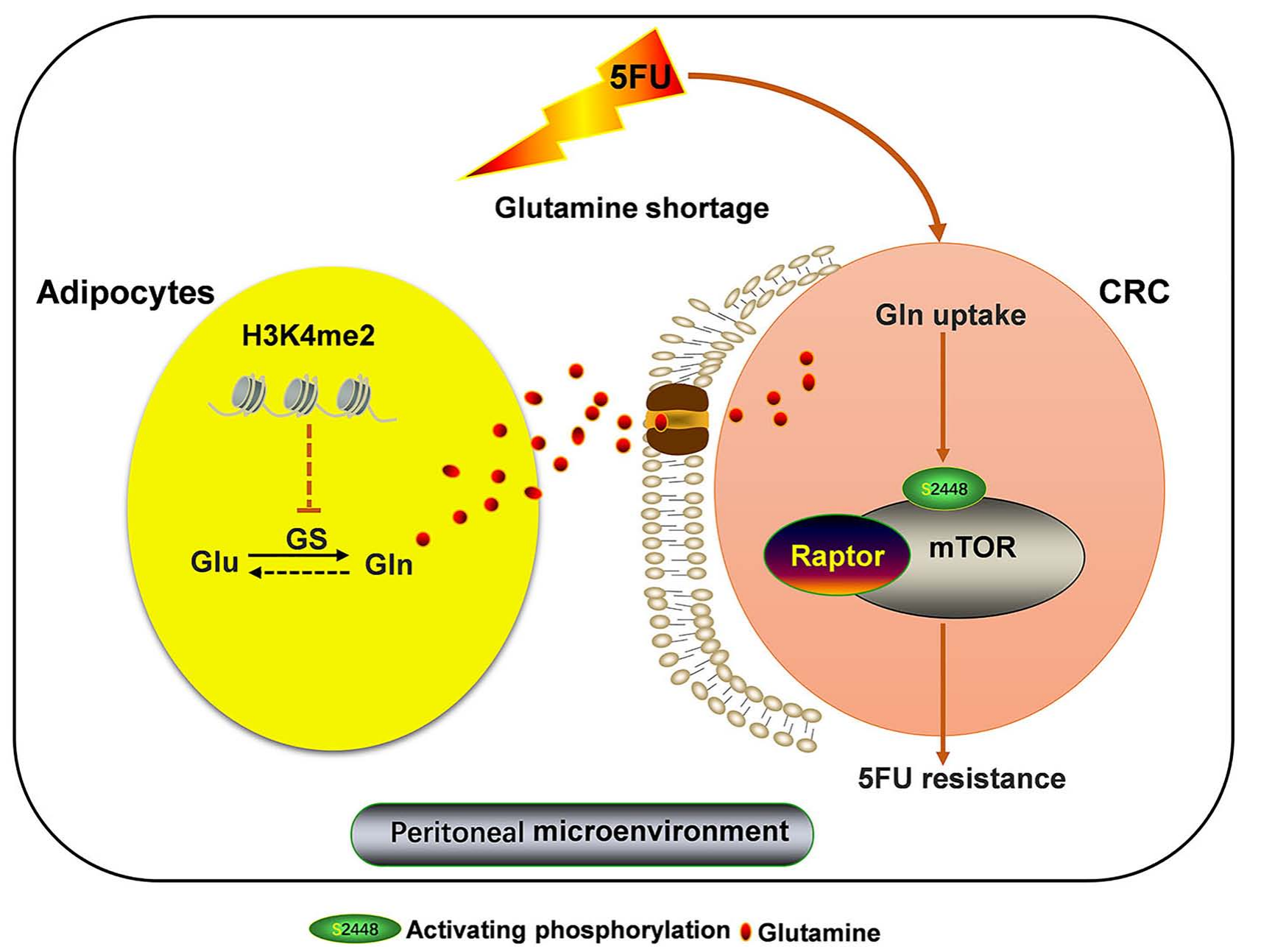

FIGURE 6 | Adipocytic GS overexpression via altered histone methylation induces chemoresistance to 5FU in peritoneal carcinomatosis of colorectal cancer metastasis. Adipocyte-derived glutamine (Gln) promotes resistance to 5FU chemotherapy via inducing mTOR activation in CRC cells. Adipocyte-derived Gln production is increased by GIn synthetase (GS) upregulation, which is regulated by altered histone methylation. Loss of H3k4me2 increases GS expression in adipose cells.

colorectal cancer. However, whether LSD1 regulated by GS-Gln axis is far from well understood. The LSD1 inhibitor GSK-LSD1 exerted a great potential in translational medicine.

Taken together, the present study identifies an underlying mechanism of chemoresistance to 5FU therapy in CRC-PC via GS upregulation in adipocytes with subsequent release of Gln. Our findings demonstrate a crosstalk between histone methylation and GS metabolism in adipocytes and suggest that tumor methionine metabolism may be an efficient target for inhibiting adipocyte-induced chemoresistance in CRC-PC.

\section{DATA AVAILABILITY STATEMENT}

The raw data supporting the conclusions of this article will be made available by the authors, without undue reservation.

\section{ETHICS STATEMENT}

The animal study was reviewed and approved by the Laboratory Animal Welfare and Ethics Committee of Army Medical University.

\section{AUTHOR CONTRIBUTIONS}

$\mathrm{XZ}, \mathrm{BW}$, and FP designed the research project. $\mathrm{XZ}$ performed mouse experiments and is a major contributor in writing the manuscript. QL performed Western blot and qPCR. AD performed cell cycle arrest assays and Annexin V apoptosis assays and proofread the revision manuscript. YL performed cell culture and cell assays. QS participated in manuscript writing. YC proofread the manuscript. YZ performed $\mathrm{HE}$ staining. BW and FP reviewed the manuscript. All authors contributed to the article and approved the submitted version. 


\section{FUNDING}

This work was supported by the National Natural Science Foundation of China (81702929) and Natural Science Foundation of Chongqing (cstc2020jcyj-msxmX0911).

\section{REFERENCES}

1. Siegel RL, Miller KD, Fuchs HE, Jemal A. Cancer Statistics, 2021. CA: Cancer J Clin (2021) 71:7-33. doi: 10.3322/caac.21654

2. Favoriti P, Carbone G, Greco M, Pirozzi F, Pirozzi RE, Corcione F. Worldwide Burden of Colorectal Cancer: A Review. Updates Surg (2016) 68:7-11. doi: 10.1007/s13304-016-0359-y

3. van Gestel YR, de Hingh IH, van Herk-Sukel MP, van Erning FN, Beerepoot LV, Wijsman JH, et al. Patterns of Metachronous Metastases After Curative Treatment of Colorectal Cancer. Cancer Epidemiol (2014) 38:448-54. doi: 10.1016/j.canep.2014.04.004

4. Lemmens VE, Klaver YL, Verwaal VJ, Rutten HJ, Coebergh JW, de Hingh IH. Predictors and Survival of Synchronous Peritoneal Carcinomatosis of Colorectal Origin: A Population-Based Study. Int J Cancer (2011) 128:2717-25. doi: 10.1002/ijc.25596

5. Kerscher AG, Chua TC, Gasser M, Maeder U, Kunzmann V, Isbert C, et al. Impact of Peritoneal Carcinomatosis in the Disease History of Colorectal Cancer Management: A Longitudinal Experience of 2406 Patients Over Two Decades. Br J Cancer (2013) 108:1432-9. doi: 10.1038/bjc.2013.82

6. Yoshimatsu K, Kato H, Ishibashi K, Hashimoto M, Umehara A, Yokomizo H, et al. Second-Line Chemotherapy With Low-Dose CPT-11 and Cisplatin for Colorectal Cancer Resistant to 5-FU-Based Chemotherapy. Cancer chemotherapy Pharmacol (2003) 52:465-8. doi: 10.1007/s00280-003-0686-9

7. Helderman R, Loke DR, Verhoeff J, Rodermond HM, van Bochove GGW, Boon M, et al. The Temperature-Dependent Effectiveness of Platinum-Based Drugs Mitomycin-C and 5-FU During Hyperthermic Intraperitoneal Chemotherapy (HIPEC) in Colorectal Cancer Cell Lines. Cells (2020) 9:1775. doi: 10.3390/cells9081775

8. Xie P, Mo JL, Liu JH, Li X, Tan LM, Zhang W, et al. Pharmacogenomics of 5Fluorouracil in Colorectal Cancer: Review and Update. Cell Oncol (2020) 43:989-1001. doi: 10.1007/s13402-020-00529-1

9. Blondy S, David V. 5-Fluorouracil Resistance Mechanisms in Colorectal Cancer: From Classical Pathways to Promising Processes. Cancer Sci (2020) 111:3142-54. doi: 10.1111/cas.14532

10. Cao Y. Adipocyte and Lipid Metabolism in Cancer Drug Resistance. J Clin Invest (2019) 129:3006-17. doi: 10.1172/JCI127201

11. Zhang F, Liu S. Mechanistic Insights of Adipocyte Metabolism in Regulating Breast Cancer Progression. Pharmacol Res (2020) 155:104741. doi: 10.1016/ j.phrs.2020.104741

12. De Angelis PM, Svendsrud DH, Kravik KL, Stokke T. Cellular Response to 5Fluorouracil (5-FU) in 5-FU-Resistant Colon Cancer Cell Lines During Treatment and Recovery. Mol Cancer (2006) 5:20. doi: 10.1186/1476-4598-5-20

13. Wappler J, Arts M, Röth A, Heeren RMA, Peter Neumann U, Olde Damink SW, et al. Glutamine Deprivation Counteracts Hypoxia-Induced Chemoresistance. Neoplasia (New York NY) (2020) 22:22-32. doi: 10.1016/j.neo.2019.10.004

14. Hu X, Jin H, Zhu L. Effect of Glutamine Metabolism on Chemoresistance and its Mechanism in Tumors. Zhejiang da xue xue bao Yi xue ban =J Zhejiang University Med Sci (2021) 50:32-40. doi: 10.3724/zdxbyxb-2021-0040

15. Feng M, Xiong G, Cao Z, Yang G, Zheng S, Qiu J, et al. LAT2 Regulates Glutamine-Dependent mTOR Activation to Promote Glycolysis and Chemoresistance in Pancreatic Cancer. J Exp Clin Cancer Res CR (2018) 37:274. doi: 10.1186/s13046-018-0947-4

16. Matés JM, Campos-Sandoval JA, Santos-Jiménez JL, Márquez J. Dysregulation of Glutaminase and Glutamine Synthetase in Cancer. Cancer Lett (2019) 467:29-39. doi: 10.1016/j.canlet.2019.09.011

17. Hua H, Kong Q, Zhang H, Wang J, Luo T, Jiang Y. Targeting mTOR for Cancer Therapy. J Hematol Oncol (2019) 12:71-1. doi: 10.1186/s13045-019-0754-1

18. Murugan AK. mTOR: Role in Cancer, Metastasis and Drug Resistance. Semin Cancer Biol (2019) 59:92-111. doi: 10.1016/j.semcancer.2019.07.003

\section{SUPPLEMENTARY MATERIAL}

The Supplementary Material for this article can be found online at: https://www.frontiersin.org/articles/10.3389/fonc.2021. 748730/full\#supplementary-material

19. Narayanankutty A. PI3K/ Akt/mTOR Pathway as a Therapeutic Target for Colorectal Cancer: A Review of Preclinical and Clinical Evidence. Curr Drug Targets (2019) 20:1217-26. doi: 10.2174/1389450120666190618123846

20. Cui X-L, Li K-J, Ren H-X, Zhang Y-J, Liu X-D, Bu B-G, et al. Extract of Cycas Revoluta Thunb. Enhances the Inhibitory Effect of 5-fluorouracil on Gastric Cancer Cells Through the AKT-mTOR Pathway. World J Gastroenterol (2019) 25:1854-64. doi: 10.3748/wjg.v25.i15.1854

21. Mariño-Ramírez L, Kann MG, Shoemaker BA, Landsman D. Histone Structure and Nucleosome Stability. Expert Rev Proteomics (2005) 2:719-29. doi: 10.1586/14789450.2.5.719

22. Audia JE, Campbell RM. Histone Modifications and Cancer. Cold Spring Harb Perspect Biol (2016) 8:a019521-a019521. doi: 10.1101/cshperspect.a019521

23. Buess M, Terracciano L, Reuter J, Ballabeni P, Boulay JL, Laffer U, et al. STRAP is a Strong Predictive Marker of Adjuvant Chemotherapy Benefit in Colorectal Cancer. Neoplasia (New York NY) (2004) 6:813-20. doi: 10.1593/neo.04307

24. Green H, Meuth M. An Established Pre-Adipose Cell Line and its Differentiation in Culture. Cell (1974) 3:127-33. doi: 10.1016/0092-8674(74) 90116-0

25. Behan JW, Yun JP, Proektor MP, Ehsanipour EA, Arutyunyan A, Moses AS, et al. Adipocytes Impair Leukemia Treatment in Mice. Cancer Res (2009) 69:7867-74. doi: 10.1158/0008-5472.CAN-09-0800

26. Taibi A, Albouys J, Jacques J, Perrin M-L, Yardin C, Durand Fontanier S, et al. Comparison of Implantation Sites for the Development of Peritoneal Metastasis in a Colorectal Cancer Mouse Model Using non-Invasive Bioluminescence Imaging. PloS One (2019) 14:e220360-e0220360. doi: 10.1371/journal.pone.0220360

27. Yang L, Zhang Y, Cheng L, Yue D, Ma J, Zhao D, et al. Mesenchymal Stem Cells Engineered to Secrete Pigment Epithelium-Derived Factor Inhibit Tumor Metastasis and the Formation of Malignant Ascites in a Murine Colorectal Peritoneal Carcinomatosis Model. Hum Gene Ther (2016) 27:26777. doi: 10.1089/hum.2015.135

28. Chen C, Chen H, Zhang Y, Thomas HR, Frank MH, He Y, et al. TBtools: An Integrative Toolkit Developed for Interactive Analyses of Big Biological Data. Mol Plant (2020) 13:1194-202. doi: 10.1016/j.molp.2020.06.009

29. Chu DT, Phuong TNT, Tien NLB, Tran DK, Nguyen TT, Thanh VV, et al. The Effects of Adipocytes on the Regulation of Breast Cancer in the Tumor Microenvironment: An Update. Cells (2019) 8:857. doi: 10.3390/cells8080857

30. Bolzoni M, Chiu M. Dependence on Glutamine Uptake and Glutamine Addiction Characterize Myeloma Cells: A New Attractive Target. Blood (2016) 128:667-79. doi: 10.1182/blood-2016-01-690743

31. Wang L, Hu B, Pan K, Chang J, Zhao X, Chen L, et al. SYVN1-MTR4-MAT2A Signaling Axis Regulates Methionine Metabolism in Glioma Cells. Front Cell Dev Biol (2021) 9:633259-9. doi: 10.3389/fcell.2021.633259

32. Thompson C, Rahman MM, Singh S. The Adipose Tissue-Derived Secretome (ADS) in Obesity Uniquely Induces L-Type Amino Acid Transporter 1 (LAT1) and mTOR Signaling in Estrogen-Receptor-Positive Breast Cancer Cells. Int J Mol Sci (2021) 22(13):6706. doi: 10.3390/ijms22136706

33. Hayashi N, Yamasaki A, Ueda S, Okazaki S, Ohno Y, Tanaka T, et al. Oncogenic Transformation of NIH/3T3 Cells by the Overexpression of LType Amino Acid Transporter 1, a Promising Anti-Cancer Target. Oncotarget (2021) 12:1256-70. doi: 10.18632/oncotarget.27981

34. Dai Q, Xie F, Han Y, Ma X, Zhou S, Jiang L, et al. Inactivation of RegulatoryAssociated Protein of mTOR (Raptor)/Mammalian Target of Rapamycin Complex 1 (Mtorc1) Signaling in Osteoclasts Increases Bone Mass by Inhibiting Osteoclast Differentiation in Mice. J Biol Chem (2017) 292:196204. doi: 10.1074/jbc.M116.764761

35. Ramapriyan R, Caetano MS, Barsoumian HB, Mafra ACP, Zambalde EP, Menon $\mathrm{H}$, et al. Altered Cancer Metabolism in Mechanisms of Immunotherapy Resistance. Pharmacol Ther (2019) 195:162-71. doi: 10.1016/j.pharmthera.2018.11.004 
36. Zhuang X, Zhang H, Hu G. Cancer and Microenvironment Plasticity: DoubleEdged Swords in Metastasis. Trends Pharmacol Sci (2019) 40:419-29. doi: 10.1016/j.tips.2019.04.005

37. Mukherjee A, Chiang CY, Daifotis HA. Adipocyte-Induced FABP4 Expression in Ovarian Cancer Cells Promotes Metastasis and Mediates Carboplatin Resistance. Cancer Res (2020) 80:1748-61. doi: 10.1158/00085472.CAN-19-1999

38. Lee JO, Kim N, Lee HJ, Lee YW, Kim SJ, Park SH, et al. Resistin, a Fat-Derived Secretory Factor, Promotes Metastasis of MDA-MB-231 Human Breast Cancer Cells Through ERM Activation. Sci Rep (2016) 6:18923. doi: $10.1038 /$ srep 18923

39. Strong AL, Ohlstein JF, Biagas BA, Rhodes LV, Pei DT, Tucker HA, et al. Leptin Produced by Obese Adipose Stromal/Stem Cells Enhances Proliferation and Metastasis of Estrogen Receptor Positive Breast Cancers. Breast Cancer Res BCR (2015) 17:112. doi: 10.1186/s13058-015-0622-z

40. Natsume M, Shimura T, Iwasaki H, Okuda Y, Hayashi K, Takahashi S, et al. Omental Adipocytes Promote Peritoneal Metastasis of Gastric Cancer Through the CXCL2-VEGFA Axis. Br J Cancer (2020) 123:459-70. doi: 10.1038/s41416-020-0898-3

41. Sun C, Li X, Guo E, Li N, Zhou B, Lu H, et al. MCP-1/CCR-2 Axis in Adipocytes and Cancer Cell Respectively Facilitates Ovarian Cancer Peritoneal Metastasis. Oncogene (2020) 39:1681-95. doi: 10.1038/s41388-019-1090-1

42. Ladanyi A, Mukherjee A, Kenny HA, Johnson A, Mitra AK, Sundaresan S, et al. Adipocyte-Induced CD36 Expression Drives Ovarian Cancer Progression and Metastasis. Oncogene (2018) 37:2285-301. doi: 10.1038/s41388-017-0093-z

43. Tan Y, Lin K, Zhao Y, Wu Q, Chen D, Wang J, et al. Adipocytes Fuel Gastric Cancer Omental Metastasis via PITPNC1-Mediated Fatty Acid Metabolic Reprogramming. Theranostics (2018) 8:5452-68. doi: 10.7150/thno.28219

44. Iwamoto H, Abe M, Yang Y, Cui D, Seki T, Nakamura M, et al. Cancer Lipid Metabolism Confers Antiangiogenic Drug Resistance. Cell Metab (2018) 28:104-17.e5. doi: 10.1016/j.cmet.2018.05.005

45. Duong MN, Cleret A, Matera EL, Chettab K, Mathé D, Valsesia-Wittmann S, et al. Adipose Cells Promote Resistance of Breast Cancer Cells to Trastuzumab-Mediated Antibody-Dependent Cellular Cytotoxicity. Breast Cancer Res BCR (2015) 17:57. doi: 10.1186/s13058-015-0569-0

46. Hanley MJ, Abernethy DR, Greenblatt DJ. Effect of Obesity on the Pharmacokinetics of Drugs in Humans. Clin pharmacokinetics (2010) 49:71-87. doi: 10.2165/11318100-000000000-00000

47. Pan ST, Li ZL, He ZX, Qiu JX, Zhou SF. Molecular Mechanisms for Tumour Resistance to Chemotherapy. Clin Exp Pharmacol Physiol (2016) 43:723-37. doi: $10.1111 / 1440-1681.12581$

48. Doktorova H, Hrabeta J, Khalil MA, Eckschlager T. Hypoxia-Induced Chemoresistance in Cancer Cells: The Role of Not Only HIF-1. Biomed Papers Med Faculty Univ Palacky Olomouc Czechoslovakia (2015) 159:16677. doi: $10.5507 /$ bp. 2015.025

49. Cascetta P, Cavaliere A, Piro G. Pancreatic Cancer and Obesity: Molecular Mechanisms of Cell Transformation and Chemoresistance. Int J Mol Sci (2018) 19:3331. doi: 10.3390/ijms19113331

50. Yu T, Guo F, Yu Y, Sun T, Ma D, Han J, et al. Fusobacterium Nucleatum Promotes Chemoresistance to Colorectal Cancer by Modulating Autophagy. Cell (2017) 170:548-63.e16. doi: 10.1016/j.cell.2017.07.008

51. Xing H, Cao Y, Weng D, Tao W, Song X, Wang W, et al. FibronectinMediated Activation of Akt2 Protects Human Ovarian and Breast Cancer Cells From Docetaxel-Induced Apoptosis via Inhibition of the P38 Pathway. Apoptosis (2008) 13:213-23. doi: 10.1007/s10495-007-0158-5

52. Matés JM, Segura JA, Campos-Sandoval JA, Lobo C, Alonso L, Alonso FJ, et al. Glutamine Homeostasis and Mitochondrial Dynamics. Int J Biochem Cell Biol (2009) 41:2051-61. doi: 10.1016/j.biocel.2009.03.003

53. Cluntun AA, Lukey MJ, Cerione RA, Locasale JW. Glutamine Metabolism in Cancer: Understanding the Heterogeneity. Trends Cancer (2017) 3:169-80. doi: 10.1016/j.trecan.2017.01.005

54. Tabe Y, Lorenzi PL, Konopleva M. Amino Acid Metabolism in Hematologic Malignancies and the Era of Targeted Therapy. Blood (2019) 134:1014-23. doi: 10.1182/blood.2019001034

55. Turowski GA, Rashid Z, Hong F, Madri JA, Basson MD. Glutamine Modulates Phenotype and Stimulates Proliferation in Human Colon Cancer Cell Lines. Cancer Res (1994) 54:5974-80.
56. Vié N, Copois V, Bascoul-Mollevi C, Denis V, Bec N, Robert B, et al. Overexpression of Phosphoserine Aminotransferase PSAT1 Stimulates Cell Growth and Increases Chemoresistance of Colon Cancer Cells. Mol Cancer (2008) 7:14. doi: 10.1186/1476-4598-7-14

57. Eelen G, Dubois C, Cantelmo AR, Goveia J, Brüning U, DeRan M, et al. Role of Glutamine Synthetase in Angiogenesis Beyond Glutamine Synthesis. Nature (2018) 561:63-9. doi: 10.1038/s41586-018-0466-7

58. Chen MK, Salloum RM, Austgen TR, Bland JB, Bland KI, Copeland Iii EM, et al. Tumor Regulation of Hepatic Glutamine Metabolism. J Parenteral Enteral Nutr (1991) 15:159-64. doi: 10.1177/0148607191015002159

59. Chen MK, Espat NJ, Bland KI, Copeland EM3rd, Souba WW. Influence of Progressive Tumor Growth on Glutamine Metabolism in Skeletal Muscle and Kidney. Ann Surg (1993) 217:655-66; discussion 666-7. doi: 10.1097/ 00000658-199306000-00007

60. Christa L, Simon M-T, Flinois J-P, Gebhardt R, Brechot C, Lasserre C. Overexpression of Glutamine Synthetase in Human Primary Liver Cancer. Gastroenterology (1994) 106:1312-20. doi: 10.1016/0016-5085(94)90024-8

61. Bode BP, Fuchs BC, Hurley BP, Conroy JL, Suetterlin JE, Tanabe KK, et al. Molecular and Functional Analysis of Glutamine Uptake in Human Hepatoma and Liver-Derived Cells. Am J Physiology-Gastrointestinal Liver Physiol (2002) 283:G1062-73. doi: 10.1152/ajpgi.00031.2002

62. Collins CL, Wasa M, Souba WW, Abcouwer SF. Regulation of Glutamine Synthetase in Human Breast Carcinoma Cells and Experimental Tumors. Surgery (1997) 122:451-63; discussion 463-4. doi: 10.1016/S0039-6060(97) 90039-8

63. Palmieri EM, Menga A, Martín-Pérez R, Quinto A, Riera-Domingo C, De Tullio G, et al. Pharmacologic or Genetic Targeting of Glutamine Synthetase Skews Macrophages Toward an M1-Like Phenotype and Inhibits Tumor Metastasis. Cell Rep (2017) 20:1654-66. doi: 10.1016/j.celrep.2017.07.054

64. Sancak Y, Peterson TR, Shaul YD, Lindquist RA, Thoreen CC, Bar-Peled L, et al. The Rag GTPases Bind Raptor and Mediate Amino Acid Signaling to Mtorc1. Sci (New York NY) (2008) 320:1496-501. doi: 10.1186/s13046-018-0947-4

65. Jewell JL, Russell RC, Guan K-L. Amino Acid Signalling Upstream of mTOR. Nat Rev Mol Cell Biol (2013) 14:133-9. doi: 10.1038/nrm3522

66. Liu D, Zhang XX, Li MC, Cao CH, Wan DY, Xi BX, et al. C/Ebp $\beta$ Enhances Platinum Resistance of Ovarian Cancer Cells by Reprogramming H3K79 Methylation. Nat Commun (2018) 9:1739. doi: 10.1038/s41467-018-03590-5

67. Hu S, Yu L, Li Z, Shen Y, Wang J, Cai J, et al. Overexpression of EZH2 Contributes to Acquired Cisplatin Resistance in Ovarian Cancer Cells In Vitro and In Vivo. Cancer Biol Ther (2010) 10:788-95. doi: 10.4161/cbt.10.8.12913

68. Cai S, Wang J, Zeng W, Cheng X, Liu L, Li W. Lysine-Specific Histone Demethylase 1B (LSD2/KDM1B) Represses P53 Expression to Promote Proliferation and Inhibit Apoptosis in Colorectal Cancer Through LSD2Mediated H3K4me2 Demethylation. Aging (2020) 12:14990-5001. doi: 10.18632/aging. 103558

69. Liu YW, Xia R, Lu K, Xie M, Yang F, Sun M, et al. LincRNAFEZF1-AS1 Represses P21 Expression to Promote Gastric Cancer Proliferation Through LSD1-Mediated H3K4me2 Demethylation. Mol Cancer (2017) 16:39. doi: 10.1186/s12943-017-0588-9

Conflict of Interest: The authors declare that the research was conducted in the absence of any commercial or financial relationships that could be construed as a potential conflict of interest.

Publisher's Note: All claims expressed in this article are solely those of the authors and do not necessarily represent those of their affiliated organizations, or those of the publisher, the editors and the reviewers. Any product that may be evaluated in this article, or claim that may be made by its manufacturer, is not guaranteed or endorsed by the publisher.

Copyright $\odot 2021$ Zhang, Li, Du, Li, Shi, Chen, Zhao, Wang and Pan. This is an open-access article distributed under the terms of the Creative Commons Attribution License (CC BY). The use, distribution or reproduction in other forums is permitted, provided the original author(s) and the copyright owner(s) are credited and that the original publication in this journal is cited, in accordance with accepted academic practice. No use, distribution or reproduction is permitted which does not comply with these terms. 